\title{
Non-Prostatic Acid Phosphatase Measurement
}

National Cancer Institute

\section{Source}

National Cancer Institute. Non-Prostatic Acid Phosphatase Measurement. NCI

Thesaurus. Code C100434.

The determination of the amount of non-prostatic acid phosphatase present in a sample. 